\title{
P-64: UV-Light-Modified Polyimide Films for Liquid-Crystal Alignment
}

\author{
S. Gong, J. Kanicki \\ University of Michigan, Ann Arbor, MI \\ L. Ma, J. Z. Z. Zhong \\ OIS Optical Imaging Systems, Northville, MI
}

\begin{abstract}
Infrared, UV-visible and X-ray photoelectron spectroscopy measurements indicate that bondbreaking and oxidation occur during broadband UVillumination of the polyimide film in the air. Surface tension and polarity are increased based on the measurements of contact angles. No obvious morphology change has been observed through atomic force microscopy analysis. While the polarized UVlight generates a relatively small pretilt angle on a nonrubbed surface, it reduces the pretilt angle to some degree on a rubbed surface, depending upon the UVlight polarization direction relative to the rubbing direction.
\end{abstract}

\section{Introduction}

Photo-induced modification of the rubbed alignment layers for liquid crystal (LC) display and rubbingless photoalignment of LC have been actively pursued during the past several years ${ }^{[1-6]}$. The photoinduced modification of the alignment layer is particularly useful for production of the multi-domain LC cells that can improve the viewing angle of active-matrix liquid crystal displays (AMLCDs). The rubbingless photoalignment can avoid the problems such as dust and electrostatic charge introduced during the rubbing process and consequently improve the production yield of AMLCDs.

In this paper, we present the effects of UV-light on both rubbed and nonrubbed polyimide films. While the LC alignment is monitored by a pretilt angle measurement, the chemical and physical changes of the polyimide films are characterized extensively by a number of experimental techniques. By analyzing the change of liquid crystal pretilt angle on rubbed polyimide films before and after polarized light UV-illumination, the mechanism of LC photoalignment is discussed.

\section{Experimental Procedure}

Nissan SE7492 (trademark) used in this study is in the form of polyamic acid. The film was spin coated on silicon wafer, quartz and glass depending on the purpose of the study. It was then cured at 180 and $250^{\circ} \mathrm{C}$ for an hour, respectively, in a nitrogen purged oven. A $200 \mathrm{~W} \mathrm{Hg(Xe)}$ lamp was used as the light source with an average power density of 40 and $10 \mathrm{~mW} / \mathrm{cm}^{2}$ for nonpolarized and polarized light, respectively, measured by a radiant power energy meter from Oriel.

The film thickness was measured by a surface profilometer and ellipsometry. Fourier transform infrared spectra were collected on a BioRad FTS-40 spectrometer.
The optical absorbance spectra were measured by a Cary $5 \mathrm{E}$ double-beam UV-visible-infrared spectrum analyzer. The atomic composition of the surface of polyimide films was determined by a Perkin-Elmer PHI 5400 X-ray photoelectron spectroscopy system using an $\mathrm{Al}$ source. The morphology of the polyimide films has been observed by a Digital Instruments scanning force microscopy in a tapping mode. The contact angle measurements were done on a stage equipped with a video-camcorder. The contact angle of both water and glycerol was measured within the first 20 seconds after the droplets contacted the surface of the film.

Polyimide films spin coated on ITO coated glass, with a thickness of around $400 \AA$ and cured at $200^{\circ} \mathrm{C}$ for 1.5 hours, were used for the pretilt angle measurements. The rubbing strength for the rubbed films was $200 \mathrm{~mm}$. The incident angle for polarized UV-illumination on rubbed films was either $45^{\circ}$ or $90^{\circ}$. The pretilt angle on nonrubbed polyimide films was generated by double linearly polarized UV-exposure method. The film was first exposed normally to S-polarized light and then to Ppolarized light with an incident angle of $45^{\circ}$. Anti-parallel cells having the same top and bottom plates were assembled for the pretilt angle measurements. The thickness of the cells was around $100 \mu \mathrm{m}$ and the cells were filled with ZLI4718 nematic LC at room temperature. The pretilt angle was measured by Fourier Optic method ${ }^{[7]}$.

\section{Experimental Results}

\section{A. Film characterization}

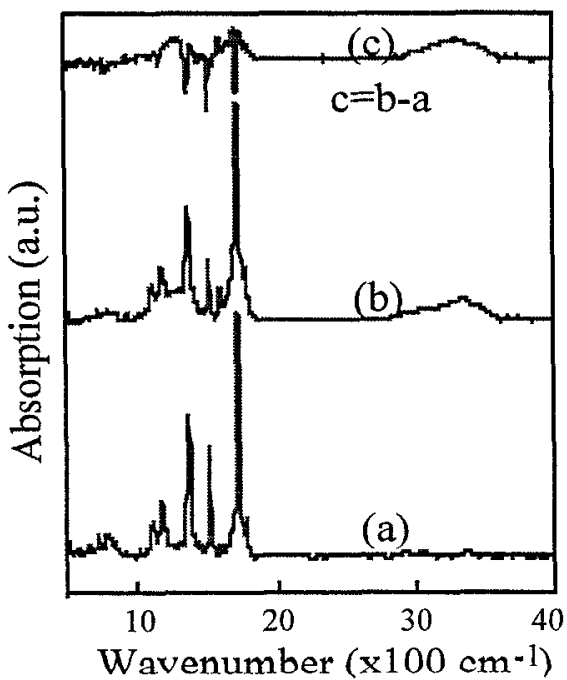

Fig. 1: FT-IR spectra of SE7492 $\left(250^{\circ} \mathrm{C}\right)$ (a) before and (b) after 90 min of UV-illumination. (c) The change induced by UV-illumination. 
Fig. 1 shows the FT-IR spectra of SE7492 $\left(250^{\circ} \mathrm{C}\right)$ before and after $90 \mathrm{~min}$ of nonpolarized UVillumination. The intensity of the characteristic absorption peaks $1722 \mathrm{~cm}^{-1}\left(\mathrm{C}=\mathrm{O}\right.$ symmetric stretching), $1372 \mathrm{~cm}^{-1}$ (C-N stretching) and $1514 \mathrm{~cm}^{-1}$ (aromatic ring) decreased after UV- illumination. Meanwhile, the intensity of the characteristic absorption peaks $1701 \mathrm{~cm}^{-1}(\mathrm{C}=\mathrm{O}$ stretching associated with $\mathrm{COOH}), 3314 \mathrm{~cm}^{-1}(\mathrm{O}-\mathrm{H}$ stretching and $\mathrm{N}-$ $\mathrm{H}$ stretching), $1605 \mathrm{~cm}^{-1}$ (C-O stretching and $\mathrm{OH}$ deformation) and $1281 \mathrm{~cm}^{-1}$ (C-O stretching) increased. Similar trend has been observed for SE7492 cured at $180^{\circ} \mathrm{C}$. These results indicate that bond-breaking and oxidation reaction occurred during the UV-illumination of the polyimide layer. This has been further confirmed by Xray photoelectron spectroscopy (XPS) analysis (Table 1). The oxygen level increased from 22.03 to $25.28 \%$ after one hour of UV-illumination. The percentage change of $\mathrm{C}-\mathrm{N}$ bond with illumination time, for SE7492 cured at different temperatures, is shown in Fig. 2. It can be seen that the UV-sensitivity of SE7492 decreased with the increase of imidization ratio.

Table 1: Surface atomic composition of SE7492 (cured at $180^{\circ} \mathrm{C}$, 1hour) obtained by XPS analysis.

\begin{tabular}{|l|l|l|l|}
\hline Sample treatment & $\mathrm{C}(\%)$ & $\mathrm{N}(\%)$ & $\mathrm{O}(\%)$ \\
\hline Unexposed & 73.01 & 4.96 & 22.03 \\
\hline UV exposed for 60 $\mathrm{min}$ & 69.51 & 5.21 & 25.28 \\
\hline
\end{tabular}

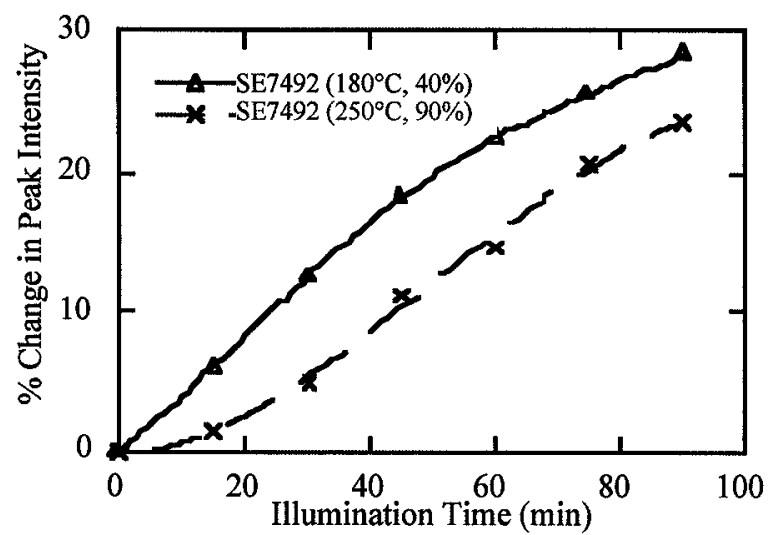

Fig. 2: The intensity change in C-N mode of SE7492 (with different imidization ratio) with UV-illumination time.

Polyimides containing aromatic and carbonyl groups have strong absorption in the UV-region as shown in Fig. 3. The UV-illuminated polyimide absorption spectra changed with the increase of UV-illumination time. The observed change represents a general trend for all polyimides involved in this study. The peak centered around $6.3 \mathrm{eV}$ is considered to be caused by the $\pi->\pi^{*}$ transition and the continuous decrease of the absorption between 4.6 and $6.5 \mathrm{eV}$ indicates the breakage of aromatic and carbonyl groups, which is consistent with IR spectra.

Based on the spectroscopic analysis, more polar groups, including $\mathrm{OH}, \mathrm{NH}$ and $\mathrm{COOH}$, have been formed after UV-illumination. Thus, a higher surface polarity after UV-illumination is expected. This was confirmed by measuring the water and glycerol contact angles on the surface of the polyimide layer. The surface tension and polarity of the polyimide films have been calculated according to the Harmonic-mean equations ${ }^{[8]}$ and the results are given in Table 2. Both surface tension and polarity have increased after UV- illumination. The change of surface tension is more dramatic for SE7492 with a lower imidization ratio.

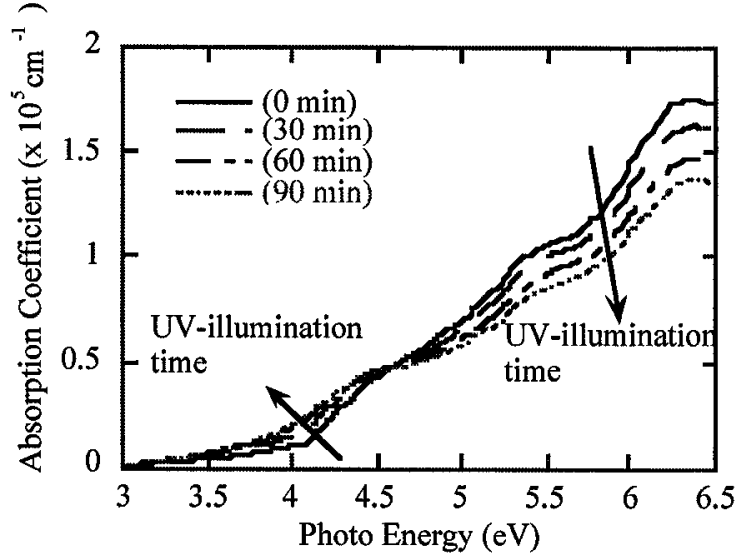

Fig. 3. The UV spectra change of SE7492 $\left(250^{\circ} \mathrm{C}\right)$ with UV-illumination time.

Table 2: Surface tension and polarity measured at different conditions.

\begin{tabular}{|c|c|c|c|}
\hline $\begin{array}{c}\text { Material } \\
\text { (curing time: } \\
1 \text { hour) }\end{array}$ & $\begin{array}{c}\text { UV-light } \\
\text { exposure } \\
\text { (min) }\end{array}$ & $\begin{array}{c}\text { Surface } \\
\text { tension }\end{array}$ & Polarity \\
\hline SE7492 $\left(180^{\circ} \mathrm{C}\right)$ & unexposed & 28.7 & 0.40 \\
\hline SE7492 $\left(180^{\circ} \mathrm{C}\right)$ & 60 & 36.3 & 0.52 \\
\hline SE7492 $\left(250^{\circ} \mathrm{C}\right)$ & unexposed & 29.9 & 0.40 \\
\hline SE7492 $\left(250^{\circ} \mathrm{C}\right)$ & 60 & 34.9 & 0.47 \\
\hline
\end{tabular}

To observe the UV-light effects on the surface morphology of the polyimide films, the films before and after UV-illumination have been studied by scanning force microscopy (AFM). Fig. 4 shows the surface images of the alignment film (a) before and (b) after $10 \mathrm{~min}$ of nonpolarized UV-illumination. The surface after $20 \mathrm{~min}$ of linearly polarized UV-illumination (c) is also shown. By comparing the surface images and the surface roughness (Ra) data, we can conclude that no obvious changes have been observed after both polarized and nonpolarized UVillumination of the nonrubbed films.

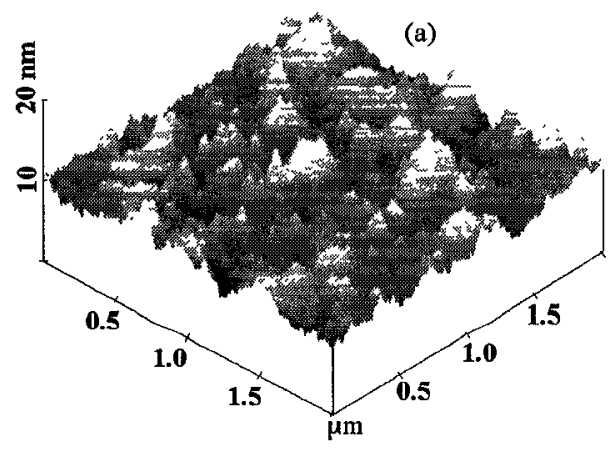

$\mathrm{Ra}=0.91 \mathrm{~nm}$ 

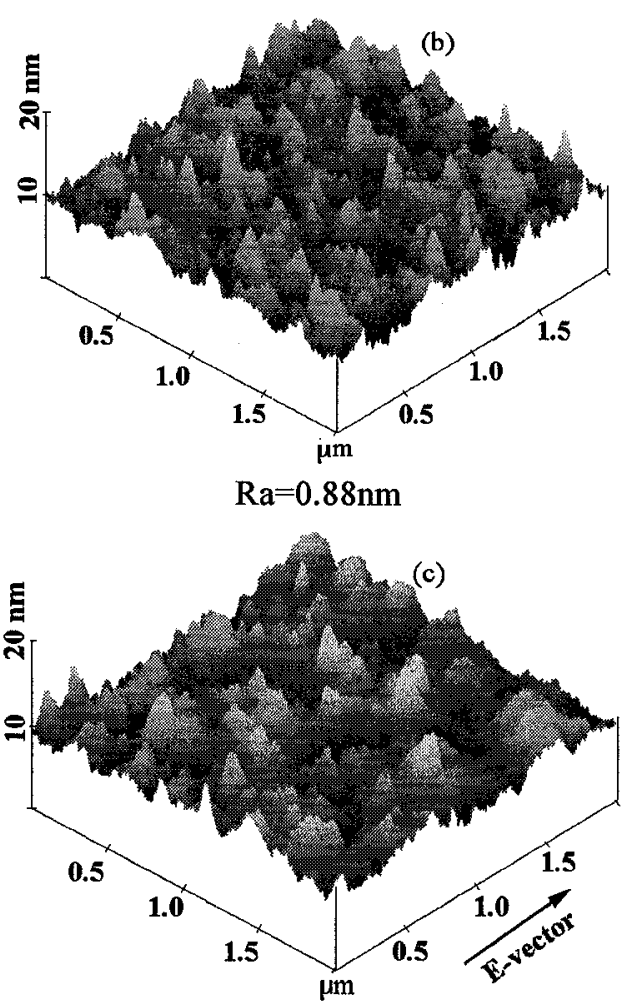

$\mathrm{Ra}=0.94 \mathrm{~nm}$

Fig. 4. AFM image of SE7492 (a) before UV-illumination (b) after $10 \mathrm{~min}$ of nonpolarized UV-illumination. (c) after $20 \mathrm{~min}$ of linearly polarized UV-illumination.

B. Pretilt angle measurements

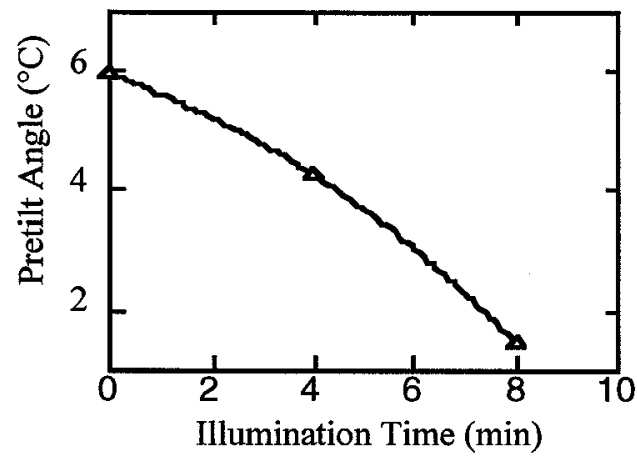

Fig. 5: The change of LC pretilt angle on rubbed films induced by nonpolarized UV-illumination.
The pretilt angle decreased after shining nonpolarized UV-light on rubbed polyimide films as shown in Fig. 5.

The LC pretilt angle on the nonrubbed polyimide films was generated by double exposure method as described in the experimental section. The LC anchoring direction was detected by observing the transmission of two different LC cells under two crossed polarizers. One surface of the LC cells is prepared by rubbing and the other surface is prepared by $20 \mathrm{~min}$ S-polarized UV-illumination. One of the two cells is assembled by aligning the rubbing direction along the E-vector of the polarized UV-light and the other one is assembled by aligning the rubbing direction perpendicular to the E-vector of the polarized UVlight. TN-type LC cell's (rubbing direction // E-vector) and anti-parallel type LC cell's (rubbing direction $\perp$ Evector) characteristics have been observed for the first and second case, respectively. This confirmed that the director of LC was aligned perpendicular to the polarization direction of the light. The pretilt angle generated at various conditions for SE7492 is shown in Table 3. The pretilt angle decreased with the increase of normal illumination time for a constant oblique illumination time. On the other hand, the pretilt angle increased with the increase of oblique illumination time for a constant normal illumination time.

Table 3: The pretilt angle change of SE7492 induced by rubbingless photoalignment.

\begin{tabular}{|c|c|l|}
\hline $\begin{array}{l}\text { Time for } \\
\text { S-polarized light } \\
\text { (normally) (min) }\end{array}$ & $\begin{array}{l}\text { Time for } \\
\text { P-polarized light } \\
\text { (incident angle: } 45^{\circ} \text { ) } \\
\text { (min) }\end{array}$ & $\begin{array}{l}\text { Pretilt } \\
\text { angle } \\
\left({ }^{\circ}\right)\end{array}$ \\
\hline 20 & 5 & 0.89 \\
\hline 20 & 10 & 1.08 \\
\hline 30 & 10 & 0.54 \\
\hline
\end{tabular}

The pretilt angle of the rubbed films after various polarized UV-illumination has also been measured and the data is summarized in Table 4. Polarized light decreased the pretilt angle in all cases. However, P-polarized light with E-vector aligned along the rubbing direction (case 1) reduces the pretilt angle more dramatically than S-polarized light with E-vector aligned perpendicular to the rubbing direction (case 2). For P-polarized light, when the rubbing direction changed from upward (case 3 ) to downward (case 4), the pretilt angles are different, e.g., the pretilt angle in case 3 is smaller in comparison with case 4 .

Table 4: The change of LC pretilt angle on rubbed films after 15 min different polarized UV-illumination.

(The LC pretilt angle on rubbed and unexposed film is $5.95^{\circ}$.)

\begin{tabular}{|c|c|c|c|}
\hline $\begin{array}{c}\text { Type of } \\
\text { polarized light }\end{array}$ & $\begin{array}{l}\text { Incident } \\
\text { angle }\left({ }^{\circ}\right)\end{array}$ & $\begin{array}{l}\text { Light incident direction, E-vector } \\
\text { and rubbing direction }\end{array}$ & $\begin{array}{l}\text { Pretilt angle } \\
\left({ }^{\circ}\right)\end{array}$ \\
\hline$P(1)$ & 90 & $\rightarrow \mathrm{light}_{\mathrm{S}} \mathrm{I} \mathrm{F}$ rubbing direction & 4.85 \\
\hline $\mathrm{S}(2)$ & 90 & rubbing direction & 5.67 \\
\hline $\mathbf{P}(3)$ & 45 & $\rightarrow$ lift $\rightarrow \mathrm{E} I>$ rubbing direction & 4.93 \\
\hline $\mathrm{P}(4)$ & 45 & $\rightarrow$ limt $\rightarrow \mathrm{E} \rightarrow$ rubbing direction & 5.21 \\
\hline
\end{tabular}




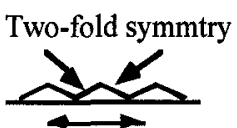

(a) LC alignment direction after S-polarized light illumination. the oblique P-polarized light.

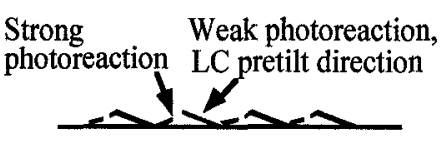

(b) Pretilt preference after oblique P-polarized light illumination.

Fig. 6 The illustration of LC alignment after polarized UV-illumination (The double exposure method has been used.).

\section{Discussion}

According to the experimental results, UVillumination induces the bond-breaking of the imide and aromatic rings, and carbonyl group. This process is combined with the oxidation reactions. Same kind of reactions have been induced by the polarized UVillumination. The formation of the more polar groups, including $\mathrm{OH}, \mathrm{NH}$ and $\mathrm{COOH}$, during this process caused the increase of both the polarity and the surface tension of polyimide surface. Based on the pretilt angle measurements, both the nonpolarized and the polarized UV-illumination decrease the pretilt angle of LC on rubbed polyimide films in all cases. Therefore, this decease is associated with the increase of surface tension after UVillumination.

The light absorption efficiency of the linearly polarized light by polyimide films follows the photoreaction coupling Hamiltonian: $\mathrm{H} \propto \mathrm{E} \bullet \mathrm{A}$, where $\mathrm{E}$ is the polarization direction of the linearly polarized light and $A$ is the transition moment of the photosensitive bonds. ${ }^{[9]}$ The different photoreaction couplings between the same functional groups aligned parallel or perpendicular to the Evector will result in different UV-light sensitivity. The bonds with transition moments aligned with E-vector are apparently more sensitive to the UV-light in comparison with those aligned perpendicular to E-vector. Therefore, anisotropic polyimide films have been formed after polarized light illumination. At the same time, no obvious surface morphology change has been observed through the AFM analysis of the polyimide surfaces before and after polarized UV-illumination. This observation indicates that the alignment of LC along the direction perpendicular to E-vector after polarized UV-illumination is not caused by the surface morphology change. Instead, it is caused by the different interaction of LC molecules with the nonreacted and the reacted polyimide bonds induced by polarized UV-illumination. Different effects of P- and Spolarized light (case 1 and 2 in Table 4) on the LC pretilt angle of the rubbed films is again caused by the different photoreaction couplings between polarized light and polyimide bonds. As shown in Table 4, the effect of Ppolarized light on the rubbed polyimide films with the rubbing direction heading upward (case 3) and downward (case 4) at the same light incident angle is also different. This indicates that the same functional groups heading upward and downward have different photoreaction couplings, i.e., the same functional groups heading upward have stronger couplings than those heading downward. Therefore, the pretilt angle was reduced more in the case of stronger photoreaction couplings (case 3). This could explain how the pretilt angle was generated by oblique Ppolarized UV-illumination during the rubbingless photoalignment of LC. During the double exposure process of the nonrubbed films, uniform alignment of LC $(\perp$ E-vector) has been achieved after S-polarized UVillumination. However, the original random pretilt does not have a preference along the alignment direction and it is two-fold symmetric as shown in Fig. 6 (a). The two-fold symmetry is broken by the oblique P-polarized UVillumination, because of the different photoreaction couplings as indicated by case 3 and 4 in Table 4 .

\section{Conclusion}

Both nonpolarized and polarized UV-illumination decrease the pretilt angle of LC on rubbed polyimide films. The pretilt angle depends on the interaction between the LC and alignment layer. The UV-illumination of polyimide films generates more polar groups at the surface by bond-breaking and oxidation process which causes the increase of surface tension and polarity. As a consequence of this process, the pretilt angle decreases with UVillumination time. The pretilt angle generated by oblique P-polarized UV-illumination during rubbingless photoalignment could be associated with the breakage of the two-fold symmetry of the original random pretilt. This mechanism is verified by the influence of the polarized UVlight on a rubbed surface of polyimide film.

\section{Acknowledgment}

Financial support for this project was provided by the Center for Display Technology and Manufacturing and the Rackham Pre-doctoral Fellowship received by Shaoqin Gong at the University of Michigan. Help from Charles Qian Li and Dan Acquard with the AFM and pretilt angle measurements, respectively, is greatly appreciated.

\section{References}

1. M.Schadt, K. Schmitt, V. Kozinkov, and V. Chigrinov, Jpn. J. Appl. Phys., 31, 2155 (1992).

2. X. Wang, D. Subacius, O. Lavrentovich, J. L. West and Y. Reznikov, SID 96 Digest, 654 (1996).

3. T. Yamamoto, M. Hasegawa and H. Hatoh, SID 96 Digest, 642 (1996).

4. K. W. Lee, A. Lien, J. Stathis and S. H. Peak, SID 96 Digest, 638 (1996).

5. Y. Limura and S. Kobayashi, SID 97 Digest, 311 (1997).

6. J. Lu, S. V. Deshpande, E. Gulari, J. Kanicki and W. L. Warren, J. Appl. Phys. 80, 5028 (1996).

7. D. Acquard and A. Abileah, Display Works'98, Digest of Technical Papers, 33 (1998).

8. S. Wu, J. Adhes., 5, 39 (1973).

9. J. Chen, D. L. Johnson, P. L. Bos, X. Wang and J. L. West, SID 96 Digest, 634 (1996). 